\title{
Identidade, oposição e pragmatismo: O conteúdo estratégico da decisão eleitoral em 13 anos de eleições
}

\author{
Elizabeth Balbachevsky \\ Universidade de São Paulo \\ Denilde Oliveira Holzhacker \\ Programa de Doutorado em Ciência Política da \\ Universidade de São Paulo
}

\begin{abstract}
Resumo
Com base em resultados de surveys realizados no contexto das quatro eleições presidenciais brasileiras de 1989, 1994, 1998 e 2002, bem como da eleição municipal de 1996), as autoras analisam o comportamento do eleitorado e propõem que este segue um padrão definido por uma dentre três estratégias possíveis: o voto como expressão de uma identidade com o candidato; como crença no potencial de oposição que o candidato representa ou como expressão da crença na sua capacidade administrativa. Ao longo do período, destaca-se a associação do voto dos eleitores que se orientam pela busca de uma identidade com o candidato e a candidatura Lula. O artigo é baseado nos resultados do Estudo Eleitoral Brasileiro.
\end{abstract}

Palavras-chave: Estudo Eleitoral Brasileiro; estratégia de voto; eleição presidencial; identidade política

\begin{abstract}
Based on survey results conducted in the Brazilian Presidential elections of 1989, 1994, 1998 and 2002 , and the local election of São Paulo in 1996, the authors analyse the electoral behavior as a result of a strategy pattern made of three possible choices: the vote as an expression of identity with the candidate; as a belief in the candidate's opposition capacity and as a belief in the candidate's administrative capacity. The authors point out the link between the vote strategy as an expression of identity with the candidate Luís Inácio da Silva, Lula, in all the period. The article is based on the Brazilian Electoral Study results.
\end{abstract}

Keywords: Brazilian Electoral Study; voting strategy; presidential election; political identity 
O entendimento do processo que leva um eleitor a definir o seu voto para um entre os vários candidatos que se apresentam em uma eleição é o objetivo primordial da análise do comportamento eleitoral. Entretanto, as respostas a esta questão tendem a gerar polêmica entre os especialistas.

Numa tradição antiga, essa escolha foi interpretada como um reflexo das clivagens sociais mais básicas da sociedade. Lipset (1968), por exemplo, argumentava que diferentes classes na sociedade capitalista tendiam a apresentar padrões distintos de votação. A escolha eleitoral, em que pese todas as mediações que possam existir, é fruto de uma decisão social coletiva e as diferenças nos padrões de votação tendem a recobrir as principais clivagens de uma sociedade.

O modelo de Michigan ${ }^{1}$, ao enfatizar como a opinião das pessoas sobre os partidos, candidatos e assuntos públicos influencia a decisão do voto, criou uma nova perspectiva de análise para o comportamento eleitoral. Dentro desta perspectiva, três variáveis são importantes para predizer o voto dos eleitores: a identidade partidária, suas opiniões sobre assuntos políticos e a imagem dos candidatos. A identidade partidária tem um valor chave neste esquema: é um elo relativamente estável do eleitor com o mundo da política e tende a condensar, num formato simbólico rarefeito, as inclinações do eleitor e suas percepções sobre a política. Esta identidade incorpora um fator psicológico, não completamente racional, que se forja ao longo do tempo, na interação do eleitor com a política. Um dos trunfos das análises de Michigan foi justamente mostrar como esta identidade é o melhor preditor da escolha eleitoral.

A escola da "escolha racional" tende a enfatizar a racionalidade da decisão do eleitor. O voto tem um caráter instrumental, o que vale dizer que, para esta escola, o eleitor é capaz de reconhecer seus interesses e, em função disto, escolher o candidato que pareça melhor representar seus objetivos (ENELOW \& HINICH, 1984). Muitos críticos apontam uma dificuldade intrínseca a este modelo, qual seja, a capacidade variável que cada eleitor tem para manipular a informação política. As respostas a esta crítica apontam para "redutores" do custo da informação: a ideologia para Downs (1957) ou a avaliação retrospectiva do desempenho do governo (FIORINA, 1981).

A realidade contemporânea das democracias ocidentais, marcada por importante decréscimo dos índices de identidade partidária no eleitorado e um crescimento da proporção de eleitores que tendem a orientar seu comportamento eleitoral em função de um conjunto limitado de questões (NEWMAN, 1986 e MILLER \& SHANKS, 1996), trouxe de volta para o centro das análises a importância

\footnotetext{
1 Survey Research Center at the University of Michigan, centro que reúne os principais estudos sobre comportamento eleitoral nos Estados Unidos desde os anos cinqüenta. As principais teses desse grupo de estudiosos foram reunidas pela primeira vez por Campbell (1960).
} 
das questões políticas e sua relevância para explicar as flutuações de curto prazo na decisão eleitoral.

Este trabalho tem por objetivo apresentar algumas evidências empíricas que vêm sendo coletadas por um grupo de pesquisadores sobre um parâmetro geral que tem se mostrado eficaz para entender a decisão de voto dos eleitores brasileiros desde a eleição de 1989. A hipótese subjacente ao presente estudo é que é possível compreender o voto como uma ação social, tal como foi definida por Touraine (1965). Assim, as motivações subjacentes à decisão do eleitor são variadas, mas obedecem a um padrão bastante definido, que pode ser compreendido considerando-se três estratégias possíveis: a expressão de uma identidade com o candidato (ou com as forças políticas que o apóiam, especialmente seu partido); o seu potencial de oposição e a sua credibilidade como político capaz de realizar os objetivos que o eleitor valoriza. Em seguida, apresentaremos os resultados dessa análise para as eleições presidenciais de 1989, 1994, 1998 e 2002, e para a eleição municipal de 1996.

\section{As pesquisas}

O primeiro survey a ser analisado por este artigo foi realizado em 1989, durante a primeira eleição presidencial depois dos governos militares. Trata-se da pesquisa "Cultura Política e consolidação democrática", com uma amostra nacional de 2.400 eleitores $^{2}$. A segunda pesquisa foi realizada em 1994, durante a eleição geral daquele ano, e cobre o estado de São Paulo, com uma amostra total de 3.000 entrevistas $^{3}$. A terceira pesquisa foi realizada durante a eleição municipal de 1996 na cidade de São Paulo, com uma amostra total de 2.000 entrevistas ${ }^{4}$. A última pesquisa foi realizada em 1998 com uma amostra nacional de 2.500 eleitores $^{5}$.

\footnotetext{
2 Pesquisa "Cultura Política e consolidação democrática". Coordenada por J.A. Moisés e J A Guilhon Albuquerque, com a participação de Jacques Mouçoçah, Elizabeth Balbachevsky, Valeriano Mendes Ferreira Costa, Jacques Bensen e Mário de Mattos, realizada a partir de um convênio entre o Departamento de Ciência Política da USP, CEDEC e Datafolha com apoio da Finep e da FAPESP. Os resultados preliminares dessa pesquisa foram publicados na edição especial sobre cultura política da revista Lua Nova. Lua Nova, n. 26, 1992.

3 Pesquisa "Tipologia do Eleitorado Paulista" (1994), coordenada por J.A. Guilhon Albuquerque (DCP. FFLCH/USP) e Carlos Alberto Bragança (DE-IME/USP), com a participação de André Singer, Elizabeth Balbachevsky e Fernando Limongi (DCP.FFLCH/USP) e Sérgio Weschler (DE-IME/USP). Assistentes de pesquisa Lourdes Inoue e Denilde Holzhacker. Financiamento FAPESP.

4 Pesquisa "Tipologia do eleitorado paulistano" (1996), coordenada por J. A. Guilhon Albuquerque (DCP. FFLCH/USP) e com a participação de Carlos Alberto Bragança (DE-IME/USP), Elizabeth Balbachevsky (DCP.FFLCH/USP) e Sérgio Weschler (DE-IME/USP). Assistente de pesquisa Denilde Holzhacker.

5 Pesquisa "Tipologia do Eleitorado Brasileiro" (1998), coordenada por J.A. Guilhon Albuquerque (DCP. FFLCH/USP) e com a participação de Carlos Alberto Bragança (DE-IME/USP) e Elizabeth Balbachevsky (DCP.FFLCH/USP). Assistente de pesquisa Denilde Holzhacker.
} 
No Brasil, os estudos sobre comportamento eleitoral vêm se consolidando lentamente e esbarram freqüentemente na falta de dados consolidados que permitam comparar a evolução do comportamento e preferências dos eleitores brasileiros ao longo do tempo. Este trabalho busca comparar os resultados obtidos nas pesquisas apresentadas acima com aqueles obtidos na pesquisa realizada em 2002 pelo estudo Eleitoral Brasileiro, ESEB, em um consórcio inter-institucional que reuniu pesquisadores de várias instituições nacionais comprometidas com o estudo do comportamento do eleitorado brasileiro. Especificamente, estamos interessadas em discutir os resultados obtidos pela aplicação de uma questão que foi repetida em todas essas pesquisas, a saber, a razão da escolha do voto ao principal cargo executivo em disputa em cada uma daquelas eleições. Em todas as pesquisas, a questão foi formulada da seguinte maneira:

Q: "Muitas pessoas que entrevistamos nos disseram o que as levou a escolher um determinado candidato. Qual dos motivos que eu vou dizer levou o(a) $\operatorname{Sr}($ a). a escolher o candidato para presidente (prefeito, em 1996)?"

As respostas, estimuladas, apresentavam a seguinte gama de opções:

"Era o candidato que melhor representava pessoas como eu" OU

"Era o candidato que estava disposto a combater os verdadeiros males do país" OU

"Era o candidato que iria trazer mais benefícios à população".

Essa questão e suas respostas pré-codificadas foram desenvolvidas em 1987, a partir dos resultados de outra pesquisa, qual seja, "Mediadores do voto no Estado de São Paulo", que buscou caracterizar as diferentes estratégias de comunicação de candidatos durante a campanha, mediante a realização de entrevistas em profundidade com candidatos à Assembléia do Estado na eleição de 1986 e seus cabos eleitorais. Os resultados indicaram que os candidatos que foram bem sucedidos na eleição de 1987 tendiam a desenvolver estratégias de comunicação que enfatizavam uma, e apenas uma, das três dimensões citadas anteriormente: o reforço da identidade do eleitor com a candidatura; o seu valor de oposição, sua capacidade de se opor a algum inimigo reconhecido como tal também pelo eleitor ou ainda a sua capacidade realizadora, sua credibilidade como

Todas as pesquisas citadas aqui, entre 1994 a 1998, utilizaram-se de um critério amostral comum que combinava informações demográficas com variáveis políticas, desenvolvido pela equipe do Prof. Dr. Carlos Alberto Bragança, do Departamento de Estatística do Instituto de Matemática e Estatística da USP. 
político capaz de ter um bom desempenho no exercício da autoridade pública. Por outro lado, as candidaturas derrotadas em geral apresentaram estratégias de campanha menos definidas: para diferentes públicos ou em diferentes momentos da campanha o candidato alternou o conteúdo da mensagem que passava aos eleitores.

Essas três alternativas correspondem às três orientações da ação social propostas por Touraine: identidade, oposição e totalidade. Segundo esse autor, a racionalidade da ação de um movimento social pode ser estabelecida a partir da identificação de sua resposta a três questões: a orientação que responde à questão "quem somos nós?", que cria uma identidade; a orientação que responde à questão "pelo que lutamos?" que, ao especificar o objeto da ação, cria um sentido de totalidade para o movimento; e, finalmente, a orientação que responde à questão "contra quem lutamos?", que singulariza um obstáculo que se interpõe entre o ator e o seu objetivo, contra qual o movimento se opõe.

O pressuposto dessas categorias é, portanto, que a decisão de voto do eleitor comporta uma dimensão de racionalidade estratégica. $\mathrm{O}$ eleitor que prioriza a identidade, busca estabelecer uma representação de si mesmo, escolhendo candidatos que melhor representem a si mesmo no processo político: o candidato que "melhor representa pessoas como eu". No voto por identificação, o eleitor valoriza sobretudo o ator e sua ação, em detrimento dos obstáculos e da realização do objetivo propriamente dito. Como ressalta Albuquerque (1992), esta escolha pode ser positiva, a identificação com alguém que quer o que eu quero, que pensa como eu e vai agir como eu agiria; ou pode ser negativa, o candidato que tem as mesmas carências que eu. Essa identidade pode ser material e imediata ou mediada por idéias e instituições. Mas, ainda assim, é expressão de uma expectativa de representação. A escolha é feita porque, de alguma forma, o eleitor estabelece um elo de identidade entre si e o candidato.

No voto por oposição, a dimensão estratégica está mais presente. Na sua opção de voto, o eleitor valoriza mais a derrota do adversário ou o combate a algum mal. Para este eleitor, é mais importante a remoção do obstáculo do que a questão de saber quem realiza a ação ou a própria concretização do objetivo. Ao votar, o eleitor busca opor-se a algo e, em função dessa oposição, escolhe o candidato: aquele que melhor se opõe àquilo que ele reconhece como um mal. Este é, muito provavelmente, o conteúdo do chamado voto por oposição, que foi a estratégia majoritária adotada pelo eleitorado brasileiro nas eleições para cargos legislativos nos anos da abertura política. Mas é também o conteúdo predominante do chamado voto "útil", o voto daquele eleitor que faz a sua opção eleitoral em função das chances relativas de cada candidato. 
Finalmente, no voto por expectativa de desempenho, o eleitor valoriza sobretudo os resultados e menos a questão de saber quem os produz ou quais são e como serão removidos os eventuais obstáculos. A escolha eleitoral é feita considerando a capacidade que cada candidato tem para realizar o objetivo perseguido pelo eleitor. É, portanto, um voto pragmático, que julga o candidato pelo que poder-se-ia chamar o seu "potencial de realizações", potencial que pode ser aferido tanto em função do desempenho passado do candidato, como pela credibilidade que este detém para ações futuras. Em muitos casos, inclusive, estas duas referências podem estar entrelaçadas, de sorte que a avaliação que o eleitor faz do desempenho do candidato no passado o credencia como um realizador no futuro ${ }^{6}$.

Entretanto, a definição do eleitor por uma dessas estratégias não é unilateral e não precede à campanha eleitoral. Esta e seus conteúdos são fatores importantes para a definição da estratégia adotada pelo eleitor na hora de votar.

\section{Motivações da escolha eleitoral: resultados em 13 anos de pesquisas}

O Gráfico 1 resume os resultados obtidos em cada uma das pesquisas mencionadas acima para a questão que descrevemos anteriormente.

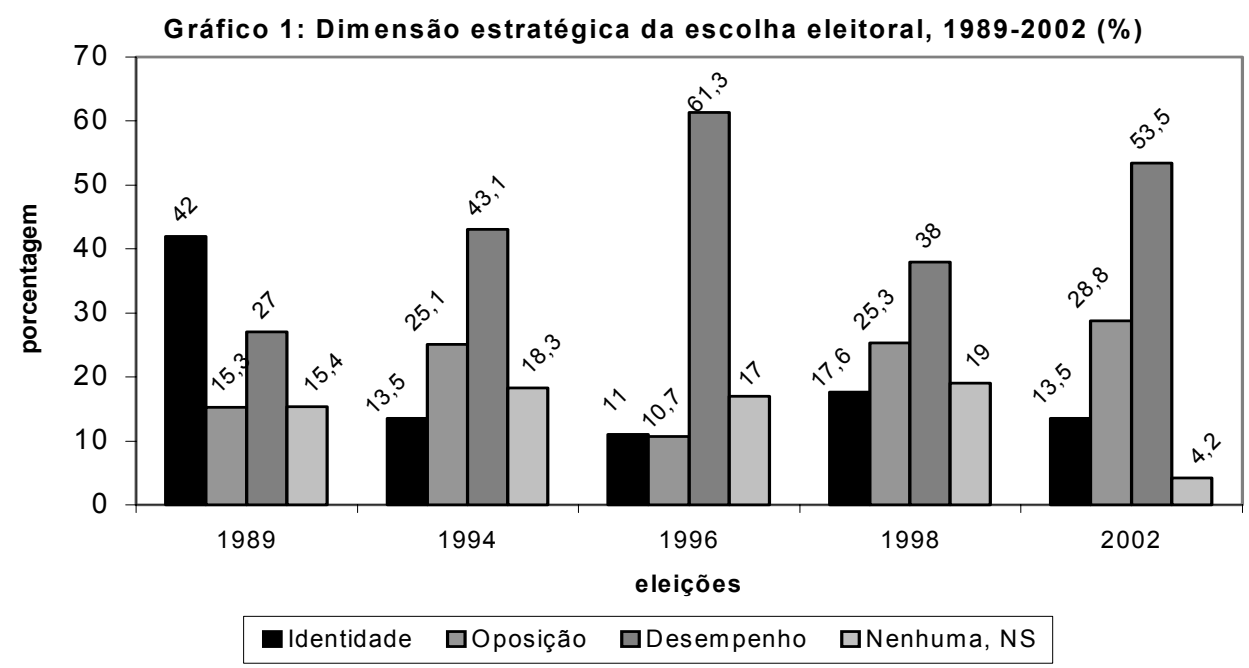

Fontes: 1989 Pesquisa Cultura Política, DCP/USP, CEDEC e Datafolha 1994-1998 Pesquisas Tipologia do Voto, NUPRI/USP 2002 Pesquisa Estudo Eleitoral Brasileiro - ESEB

\footnotetext{
${ }^{6}$ A literatura internacional tem insistido nesta dimensão e no seu potencial preditor da escolha do eleitor (FIORINA, 1981). Nosso artigo reconhece esta discussão. Entretanto, argumentamos que considerações desta ordem são importante apenas para a parcela do eleitorado que faz a sua escolha eleitoral utilizando considerações pragmáticas: quem será o melhor candidato (ou o mais credenciado) para fazer aquilo que o eleitor considera necessário.
} 
Como é possível verificar, na pesquisa realizada na eleição de 1989 a maior parte dos entrevistados tendeu a escolher seu candidato privilegiando sua identidade com este. Ao todo, $42 \%$ dos eleitores entrevistados naquela pesquisa declararam ter escolhido seu candidato porque era quem melhor representava pessoas como eles. Naquela eleição, apenas 15,3\% dos eleitores indicaram ter escolhido seu candidato em função de seu conteúdo oposicionista e outros $27 \%$ dos entrevistados escolheram seu candidato considerando seu "potencial para realizações", ou a sua credibilidade para o desempenho.

Entretanto, nas eleições subseqüentes para as quais temos informação, todas realizadas após o Plano Real (1994), essas proporções se alteram e tendem a repetir um mesmo padrão. Desde 1994, uma grande parcela do eleitorado optou sempre por escolher a alternativa que descreve expectativas quanto ao desempenho dos candidatos como aquela que melhor descrevia as razões de sua escolha eleitoral. De fato, na pesquisa eleitoral de 1994, essa motivação foi apontada por 43,1\% dos entrevistados; em 1996, essa foi a razão escolhida por $61,3 \%$ dos eleitores paulistanos; em 1998, essa resposta foi escolhida por $38 \%$ dos entrevistados e, na pesquisa eleitoral de 2002, 53,5\% dos entrevistados voltaram a escolher essa alternativa como aquela que melhor explicava sua decisão eleitoral. 0 potencial de oposição do candidato foi apontado como razão do voto por $25,1 \%$ dos entrevistados em 1994, 10,7\% dos entrevistados em 1996, 25,3\% dos entrevistados em 1998 e 28,8\% dos entrevistados em 2002. Já a identidade com o candidato foi apontada como razão para a escolha por $13,5 \%$ dos eleitores em 1994; 11\% dos entrevistados em 1996, 17,6\% em 1998 e 13,5\% dos eleitores entrevistados em 2002.

Observando os dados, podemos dizer que, nas eleições presidenciais selecionadas, as expectativas de desempenho ou o potencial de realizações do candidato de um lado e, de outro, o potencial de representação e de identificação do candidato polarizaram a atenção do eleitor e ajudaram em sua decisão de voto.

Para a única eleição municipal aqui analisada, a eleição de 1996 na capital paulista, uma importante maioria dos eleitores entrevistados relatou ter decidido seu voto em função das expectativas de desempenho que associavam ao candidato por eles escolhido: assim, 61,3\% dos eleitores paulistanos apresentaram esta resposta, contra apenas $11 \%$ que disseram ter escolhido seu candidato em função de sua capacidade de representar pessoas como ele. Somente 10,7\% dos entrevistados declararam ter escolhido seu candidato em função de sua capacidade de se opor. Este quadro é congruente com a imagem que usualmente se tem das eleições municipais, em que, mesmo nas grandes metrópoles, a solução de problemas locais ganha peso na agenda que define as escolhas dos eleitores. 0 potencial de realização de cada candidato, isto é, sua credibilidade como um "bom administrador", é um fator de peso na decisão eleitoral. 


\section{Motivação do voto e candidaturas: a dinâmica de cada campanha}

Uma outra questão relevante desta análise consiste em verificar em que medida as dimensões descritas acima estão correlacionadas com diferentes candidaturas que disputaram a preferência do eleitor nas referidas eleições. Também é possível verificar um padrão bastante estável, com associações que se repetem de eleição para eleição. O Quadro 1, a seguir, apresenta os resultados obtidos pelo cruzamento desta questão com a opção de voto declarada pelo eleitor em cada eleição.

\section{Quadro 1}

Voto no $1^{\circ}$ turno nas eleições presidenciais de 1989, 1994, 1998, 2002 e para a capital paulista em 1996 e a razão de voto

\begin{tabular}{|c|c|c|c|c|c|}
\hline \multirow{2}{*}{ Ano } & \multirow{2}{*}{ Cand. } & \multicolumn{3}{|c|}{ Razão do Voto } & \multirow{2}{*}{ Total } \\
\hline & & Identidade & Oposição & Desempenho & \\
\hline \multirow{4}{*}{1989} & Collor & 33,1 & 21,8 & 54,0 & 37,7 \\
\hline & Lula & 26,9 & 14,2 & 16,8 & 21,3 \\
\hline & Outros & 40,1 & 64,0 & 29,2 & 41,0 \\
\hline & Total $(100 \%)$ & $(826)$ & $(303)$ & (531) & (1660) \\
\hline \multirow{4}{*}{1994} & $\mathrm{FHC}$ & 53,1 & 68,0 & 71,3 & 67,2 \\
\hline & Lula & 32,6 & 20,7 & 19,2 & 21,9 \\
\hline & Outros & 14,3 & 11,3 & 9,5 & 10,9 \\
\hline & Total & $(350)$ & $(646)$ & $(1103)$ & (2099) \\
\hline \multirow{4}{*}{1996} & Pitta & 36,0 & 46,6 & 57,9 & 53,5 \\
\hline & Erundina & 31,0 & 23,8 & 22,5 & 23,8 \\
\hline & Outros & 33,0 & 29,5 & 19,5 & 22,6 \\
\hline & Total $(100 \%)$ & (197) & (193) & (1091) & (1481) \\
\hline \multirow{4}{*}{1998} & $\mathrm{FHC}$ & 40,5 & 49,3 & 54,5 & 49,8 \\
\hline & Lula & 40,7 & 34,0 & 29,1 & 33,2 \\
\hline & Outros & 18,8 & 16,8 & 16,4 & 17,0 \\
\hline & Total $(100 \%)$ & (378) & (536) & (794) & (1708) \\
\hline \multirow{6}{*}{2002} & Lula & 60,8 & 56,4 & 51,1 & 53,2 \\
\hline & Ciro & 7,5 & 10,8 & 10,0 & 9,9 \\
\hline & Serra & 19,0 & 22,0 & 24,3 & 23,2 \\
\hline & Garotinho & 11,6 & 10,3 & 14,1 & 12,9 \\
\hline & Outros & 1,1 & 0,5 & 0,6 & 0,8 \\
\hline & Total $(100 \%)$ & (268) & (573) & $(1065)$ & (1906) \\
\hline \multicolumn{2}{|c|}{ 1989: $\mathrm{Chi}^{2}: 153,222$} & Grau de Liberdade: 4 & \multicolumn{2}{|c|}{ Significância.: 0,000} & \\
\hline 1994: $\mathrm{Ch}$ & 40,965 & Grau de Liberdade: 4 & \multicolumn{2}{|c|}{ Significância.: 0,000 } & \\
\hline 1996: Ch & 39,948 & Grau de Liberdade: 4 & \multicolumn{2}{|c|}{ Significância.: 0,000 } & \\
\hline \multicolumn{2}{|c|}{ 1998: Chi²: 409,509} & Grau de Liberdade: 4 & \multicolumn{2}{|c|}{ Significância.: 0,000 } & \\
\hline \multicolumn{2}{|c|}{ 2002: $\mathrm{Chi}^{2}: \quad 41.743$} & Grau de Liberdade: 8 & \multicolumn{2}{|c|}{ Significância: 0,000} & \\
\hline
\end{tabular}


Os resultados apresentados no Quadro 1 impressionam pela sua estabilidade. Em todas as eleições presidenciais estudadas, podemos constatar uma associação positiva e significativa entre a candidatura de Lula e os eleitores que votam buscando estabelecer uma identidade com o candidato. 0 resíduo ajustado calculado para as células que descrevem essa associação é alto e significativo. Em 1989, enquanto $21,3 \%$ dos eleitores pesquisados declararam ter votado em Lula, essa proporção subia para $26,9 \%$ entre os eleitores que disseram escolher seu candidato considerando a sua capacidade de representar pessoas como o eleitor. Em 1994, ao todo, 21,9\% dos entrevistados declararam ter votado em Lula no primeiro turno, mas essa proporção subia para $32,6 \%$ entre os eleitores que decidiram seu voto por identidade. Em 1998, novamente, os votos em Lula somavam $33,2 \%$ dos eleitores, mas eram $40,7 \%$ entre aqueles que votavam por identidade. Finalmente, na pesquisa realizada em 2002, enquanto no total, 53,2\% dos eleitores declararam ter votado em Lula, essa proporção subiu para $60,8 \%$ quando foram considerados apenas os eleitores que disseram escolher seu candidato porque era aquele que melhor representava pessoas como o próprio eleitor.

Portanto, podemos dizer que a candidatura Lula, ao longo desses treze anos, mobilizou especialmente o eleitorado que buscava, ao votar, expressar sua identidade com o candidato escolhido. Por outro lado, em 1989 essa candidatura perdeu uma proporção significativa de votos entre os eleitores que tendiam a definir seu voto em função das suas expectativas de desempenho do candidato. Naquele ano, o voto em Lula foi a opção de apenas 16,8\% desses eleitores, contra $21,3 \%$ no total da amostra. Na eleição de 1994 e 1998, a candidatura Lula não conseguiu mobilizar significativamente esses eleitores. Nestas mesmas eleições Lula obteve, respectivamente, $19,2 \%$ e $29,1 \%$ dos votos dos eleitores que declararam ter escolhido seus candidatos em função de sua credibilidade para trazer benefícios.

Por outro lado, tanto na eleição de 1989 como nas eleições de 1994 e 1998, o candidato vitorioso tendeu a concentrar o voto dos eleitores que decidiram seu voto em função da expectativa de desempenho do candidato. Em 1989, a candidatura de Collor de Melo atraiu os votos de $54 \%$ desses eleitores, contra $37,7 \%$ apurados na amostra total. Em 1994, Fernando Henrique Cardoso obteve $71,3 \%$ dos votos desses eleitores, tendo obtido $67,2 \%$ dos votos no total da amostra e, em 1998, este candidato obteve 54,2\% dos votos desses eleitores, contra $49,8 \%$ na amostra total. Para todas estas eleições, essas diferenças são positivas e significativas. 
Nas eleições de 1994 e de 1998, a candidatura de FHC sofreu um importante e significativo revés entre os eleitores que escolheram seu candidato em função da sua identidade. Em 1994, a proporção de votos em FHC entre esses eleitores caiu de $67,2 \%$ do total da amostra para 53,1\%. Em 1998, a queda foi de $49,8 \%$, proporção registrada na amostra, para 40,5\%, proporção registrada entre estes eleitores.

O conjunto dos resultados permite entender a dinâmica das campanhas eleitorais na década de noventa e, ao mesmo tempo, identificar a força e a fraqueza das candidaturas de Lula e FHC no período. De fato, nessas eleições, uma explicação para o sucesso da candidatura FHC é justamente a sua credibilidade como realizador. O sucesso do Plano Real deu a esse candidato um trunfo específico para disputar a preferência do voto dos eleitores que se inclinavam a se decidir em função das suas expectativas e realizações do futuro governo. Observe-se que não estamos dizendo que o voto em FHC foi um voto de aprovação retrospectiva, do desempenho passado do Presidente, mas sim que esse desempenho passado dava credibilidade para o candidato propor futuras realizações. Por outro lado, as dificuldades enfrentadas por esta candidatura em forjar laços mais fortes de identidade com seu eleitorado representaram uma limitação importante. À medida que, com o passar do tempo, outras questões avolumavam-se na agenda do governo federal e o impacto do Plano Real se desvanecia, a força da candidatura tendeu a diminuir. Já na eleição de 1998 os resultados da pesquisa permitiam sustentar a hipótese de que a vitória de $\mathrm{FHC}$ naquele ano era produto mais da incapacidade da oposição de se apresentar como uma alternativa viável de governo do que do potencial eleitoral intrínseco do candidato à reeleição (ALBUQUERQUE et al, 1999).

A eleição municipal de 1996 apresenta um quadro em muitos pontos similar àquele que traçamos acima: o candidato vitorioso, Pitta, polarizou os votos dos eleitores que votavam em função de suas expectativas de desempenho do futuro governante (57,9\% dos votos desses eleitores, contra 53,4\% na amostra total), ao passo que a sua principal adversária naquela eleição, Luíza Erundina, foi melhor sucedida em atrair os eleitores que votaram por identificação: entre esses eleitores, Erundina obteve $31 \%$ dos votos, contra $23,8 \%$ no total da amostra. Naquela eleição, a pesquisa realizada mostrou que a credibilidade de Pitta estava associada à avaliação positiva que o eleitorado paulistano fazia da administração anterior, de Paulo Maluf, patrocinador da sua campanha. De fato, na análise que realizamos na época, a avaliação que este eleitorado fazia da administração de Paulo Maluf era a variável de maior poder preditivo para a decisão do eleitor. A associação entre essas duas variáveis permaneceu forte mesmo entre eleitores que declararam ter identidade partidária com o Partido dos Trabalhadores. Naquela eleição, Pitta recebeu apenas $10 \%$ dos votos dos eleitores identificados com o PT. Porém, entre 
esses eleitores que também faziam uma avaliação positiva da administração de Maluf, essa proporção subia para $38 \%$.

A pesquisa eleitoral que cobriu a eleição de 2002 mostrou que, do ponto de vista da composição do seu eleitorado na dimensão que estamos analisando, a candidatura Lula apresentou poucas mudanças. Lula permaneceu com um forte potencial de atração entre os eleitores que decidiram seu voto em função da sua identificação com o candidato (resíduo ajustado de 2,7) e teve um pequeno, mas significativo decréscimo na votação entre os eleitores que decidiram seu voto considerando as suas expectativas de desempenho (resíduo ajustado de -2,1). Já a candidatura de Serra, principal adversário do candidato do PT, fugiu daquele padrão observado para a candidatura do PSDB nas eleições anteriores. Ao contrário de FHC, Serra não foi capaz de mobilizar o eleitorado que define seu voto em função de suas expectativas sobre o futuro desempenho do governante. A votação de Serra, entre esses eleitores, não foi significativamente diferente daquela que se observou no total da amostra, como também não o foi entre eleitores que adotaram outras perspectivas para definir seu voto. As candidaturas de Ciro e de Garotinho também se apresentaram igualmente indiferenciadas na dimensão que estamos estudando. Esses dados são coerentes com a hipótese de que o fracasso da candidatura Serra decorre, em grande medida, de sua indiferenciação para o eleitorado. A credibilidade que gozava FHC nas eleições anteriores como um candidato capaz de realizar e trazer benefícios para a população não se transferiu em 2002 para o candidato do governo como também nenhum outro candidato foi capaz de atrair significativamente o eleitorado que votou na expectativa de que o novo governo fosse capaz de trazer benefícios. Essa parcela do eleitorado, ainda que representasse a maior parte dos eleitores, não esteve associada com nenhuma das candidaturas que disputaram a eleição. Mesmo o sucesso da candidatura Lula deve ser explicado por outras variáveis, já que também ela não polarizou esse eleitorado.

Resta saber qual o sucesso que Lula, presidente eleito em 2002, terá em associar sua figura pública a um conjunto bem sucedido de políticas (e avaliadas como tais), capaz de mobilizar o eleitorado que tem essa expectativa dos governantes. Caso seja bem sucedido, sua candidatura à reeleição será muito fortalecida. Isto porque ele beneficiar-se-ia também da sua forte identidade com outra parcela do eleitorado. Caso contrário, suas chances futuras de vitória ou derrota dependerão muito mais da fortuna que da sua virtú pessoal. Em um cenário assim, o resultado da eleição dependerá da competência da oposição para construir uma candidatura com fortes credenciais para disputar o eleitorado que vota em função de suas expectativas de desempenho do futuro governo. 


\section{Bibliografia}

ALBUQUERQUE, J. A. G. Identidade, oposição e pragmatismo: uma teoria política do voto. Revista Lua Nova, p. 53-80, 1992.

ALBUQUERQUE, J. A. G.; BALBACHEVSKY, E. \& HOLZHACKER, D. Os impactos da crise financeira sobre a opinião pública brasileira. Revista Brasileira de Comércio Exterior (RBCE), n. 58, ano XIII, 1999.

CAMPBELL, A.; CONVERSE, P. E.; MILLER, W. \& STOKES, D. The American voter. New York: John Wiley, 1960.

DOWNS, A. An economic Theory of Democracy. New York: Harper \& Row, 1957.

ENELOW, J \& HINICH, M. The spatial theory of voting: an introduction. Cambridge MS: Cambridge University Press, 1984.

FIORINA, M. Retrospective voting in american national elections. New Haven: Yale University press, 1981.

LIPSET, S. M. O homem político. Rio de Janeiro: Zahar editores, 1968.

MILLER, W. E. \& SHANKS, J. M. The new american voter. Cambridge, MS and London: Harvard University Press, 1996.

NEWMAN, W. R. The paradox of mass politics. Cambridge, MS, London: Harvard University press, 1986.

TOURAINE, A. Sociologie de L'Action. Paris: Seuil, 1965. 